\title{
Streamflow Estimation Using Regionalized Hydrometeorological Assessment on Associated Ungauged Small Watershed: A Case Study at West Nusa Tenggara Province
}

\author{
Dian Indrawati ${ }^{1,2^{*}}$ Auroop R. Ganguly ${ }^{2}$ Kemal Taruc $^{3}$ Bagus Yakti $^{1}$ \\ ${ }^{1}$ Civil Engineering Departement, Universitas Jenderal Achmad Yani, Cimahi, West Java, Indonesia \\ ${ }^{2}$ Sustainability \& Data Sciences Laboratory, Department of Civil \& Environmental Engineering, Northeastern \\ University, Boston, MA, USA \\ ${ }^{3}$ Civil Engineering Departement, Universitas 17 Agustus 1945 Surabaya, Surabaya, East Java, Indonesia \\ *Corresponding author. Email: dian.indrawati@lecture.unjani.ac.id
}

\begin{abstract}
Small watershed has a quick response of both meteorological and hydrological variables which led to the critical impact of discharges, especially for a small island. However, the watershed generally has lacked ground observation data. Thus, many engineers and scientists have used the geostationary satellite to develop a continuous data observation, such as Tropical Rainfall Measuring Mission (TRMM) and recently Global Precipitation Measurement (GPM). Unfortunately, the environmental factor could generate anomalies for the satellite sensor data; hence, hydrological characteristics for the small island are varied. Therefore, several calibrations using ground stations data are necessary to provide reliable results. This paper proposes a regionalized hydrometeorological assessment for streamflow prediction on ungauged small watersheds at part of Sumbawa Island, Nusa Tenggara Barat province, Indonesia. First, a block of satellite data is developed which covered ungauged watersheds, ground rainfall stations, and Automatic Water Level Recorder (AWLR) station. Next, an analysis of topography, land cover, and soil types are developed to identify homogenous hydrology factors of watersheds. After several corrections on daily rainfall data using the reliable ground station on homogenous meteorological conditions are done, the discharge will be calibrated using water level data from another gauged watershed for developing hydrology variable references. Values of coefficient of correlation were $\geq 0.60$ during the correction, validation, and calibration phases. Based on this assessment, the regionalized hydrometeorological shows a satisfactory result on the small watershed for the streamflow estimation. This assessment is important for managing ungauged watersheds in an uncertain climate, especially for developing a reliable discharge for the infrastructure utilization.
\end{abstract}

Keywords: Regionalized analysis, Ungauged watershed, Satellite data, Streamflow estimation.

\section{INTRODUCTION}

Developing reliable streamflow data are a highly important critical step to provide effective designs for infrastructures and watershed management, especially for a dam [1]. However, the complexity of forecast precipitation and development of reliable streamflow data are challenging tasks for the hydrology analysis [2] [3]. A holistic understanding of meteorological and hydrological features in both global and local conditions is necessary since all of them further influence rainfallrunoff values in a watershed. Since the watershed environments are varied, simplifying their characteristics will lead to inaccurate results [4].

In addition, developing an assessment about streamflow data in ungauged watershed especially with small basins is quite challenging. It is due to the process of obtaining equivalent variables from gauged watershed which has similar meteorological and hydrology, as well as appropriate temporal and spatial conditions, are complex works [3] [5]. Generally, a small island has various hydro-meteorological conditions, such as rainfall, which can extremely differ between adjacent 
areas due to the extreme changes in altitude. On the other hand, a small watershed has a quick response of both meteorological and hydrological variables which led to the critical impact of streamflow.

On the other hand, satellite remote sensing data regarding climate records is progressively improved for the last few decades. Satellite remote sensing has provided such an effective tool for gathering topography, atmospheric profiles, properties of the cryosphere, thermosphere, ionosphere, and magnetosphere [6]. The Tropical Rainfall Measuring Mission (TRMM) becomes one of the reliable satellite data for the climate which has a fine-scale and shows a positive correlation with gauging ground station data [7] [8]. The satellite data was further combined with ground station data in the gauging watershed as a calibration to provide reliable synthetic data. In which, The International Association of Hydrological Sciences (IAHS) recommended three techniques for predicting the streamflow in the ungauged watershed, i.e.: the physical similarity, radar altimetry, and regression method [3].

Sumbawa, one of the small islands in eastern Indonesia, has a special condition. It is struggling for both surface and groundwater availability. Therefore, it needs numerous infrastructures for capturing as much rainfall. This island has \pm 400 dams and small dams. For collecting the hydrometeorology data, Sumbawa has 117 rainfall stations (both manual and automatic), 11 water level recorder stations, and 11 climate stations (see Fig. 1). However, most of the rainfall stations, water level recorder, and climate recorder were not integrated into one watershed. Therefore, sometimes they have various results for two nearest dams that have similar hydrology conditions because they used different data.

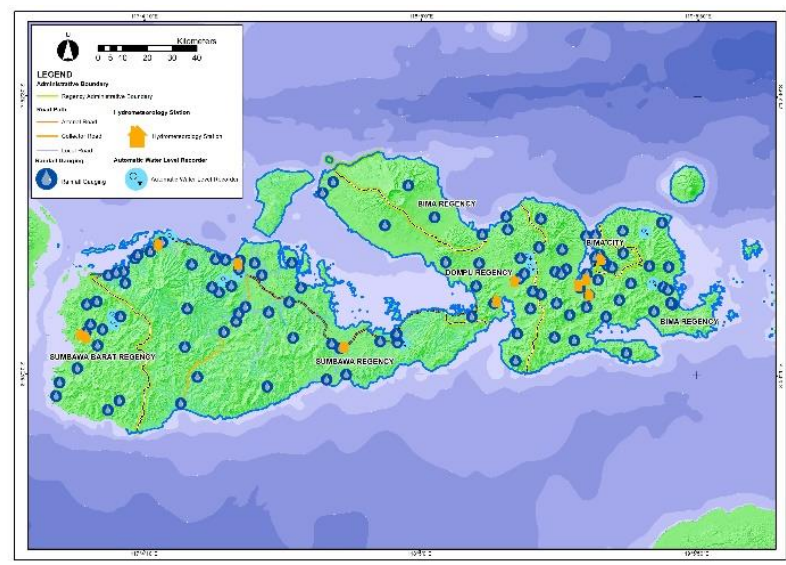

Figure 1 Rainfall stations, water level stations, and climate stations in Sumbawa Island.

This paper proposed a regionalized hydrometeorological assessment for streamflow prediction on several ungauged small watersheds at part of Sumbawa Island, West Nusa Tenggara province, Indonesia and takes a small watershed on a small island as the example. Data will be derived from TRMM, especially 3B42 daily data (TMPA) Precipitation L3 1 day 0.25 -degree $\times 0.25$ degree $\mathrm{V7}$ data which have $180.0,-50.0,180.0,50.0$ spatial coverage and 1998-01-01 to 2020-01-01 temporal coverage.

Next, the selected satellite data will be corrected with ground station data which have long and similar historical precipitation data as well as have equal hydrology conditions. Furthermore, calibration will be held by using daily discharge from water recorder station data to develop reliable streamflow data.

\section{STUDY AREA AND DATASETS}

Sumbawa Island, located in West Nusa Tenggara province, Indonesia, has geographic coordinate $05^{\circ} 54^{\prime}$ $09^{\circ} 07^{\prime} \mathrm{S}$ and $117^{\circ} 42^{\prime}-119^{\circ} 05^{\prime} \mathrm{E}$. This island covers four districts, i.e: Bima city, Bima district, Dompu district, Sumbawa district and Sumbawa Barat district with $15,319.450 \mathrm{~km}^{2}$ area. Sumbawa is also divided into 555 watersheds with various hydro-meteorology characteristics.

This study will focus on developing reliable streamflow data for the Sanggupasante dam, which is in Dompu district, West Nusa Tenggara province, Indonesia. This dam has a geographic coordinate $08^{\circ} 29^{\prime}$ $26.09^{\prime \prime} \mathrm{S}$ and $118^{\circ} 17^{\prime} 43.67^{\prime \prime}$ E. The inflow comes from two seasonal rivers with $5.893 \mathrm{~km}^{2}$ total area of the watershed, $6.00 \mathrm{~km}$ length of the main river, 0.04 mean slope, 81.60 composite $\mathrm{CN}$ and $935.62 \mathrm{~mm}$ average yearly rainfall. This watershed is in the semi-arid zone with a maximum probability rainfall amount between 600 $\mathrm{mm}$ and $650 \mathrm{~mm}$ [9].

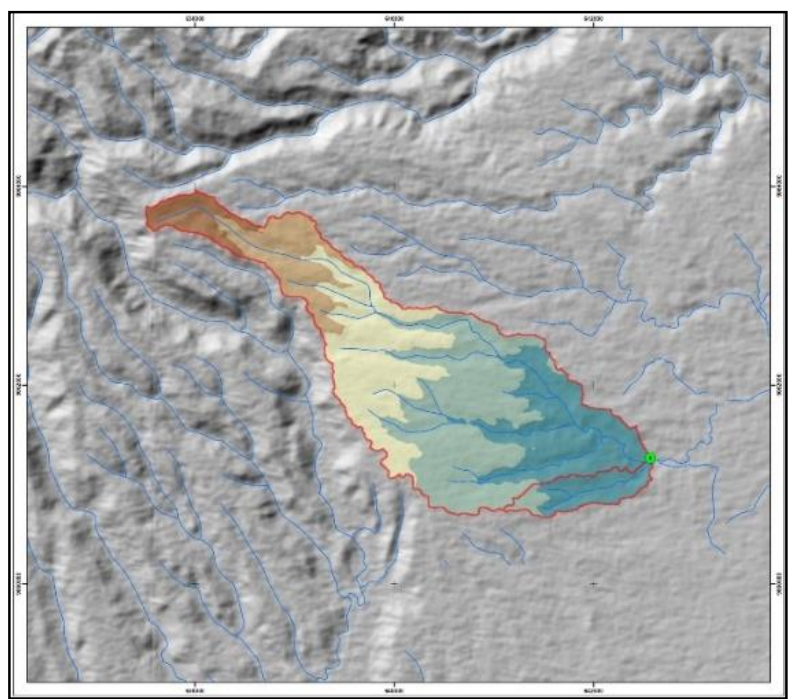

Figure 2 The Sanggupasante dam catchment area

Recently, the nearest reliable rainfall station is only Gapit station, which has $08^{\circ} 50^{\prime} 7.09^{\prime \prime} \mathrm{S}$ and $117^{\circ} 56^{\prime}$ $29.29 " \mathrm{E}$ and is in an arid zone with a maximum probability rainfall amount between $450 \mathrm{~mm}$ and $500 \mathrm{~m}$ [9]. For the discharge data calibration, this research used 
the Tawali station, which has $08^{\circ} 18^{\prime} 05.99^{\prime \prime} \mathrm{S}$ and $118^{\circ}$ 50 ' 02.00 " $\mathrm{E}$ and is located in an arid zone with a maximum probability rainfall amount between $450 \mathrm{~mm}$ and $500 \mathrm{~m}$ [9]. Furthermore, the TRMM data were developed from 41, 42, 43, 44, 45, 53, 54, 55, 56, 57, 65, $66,67,68$, and 69 grids which covered all those stations (see Fig. 3).

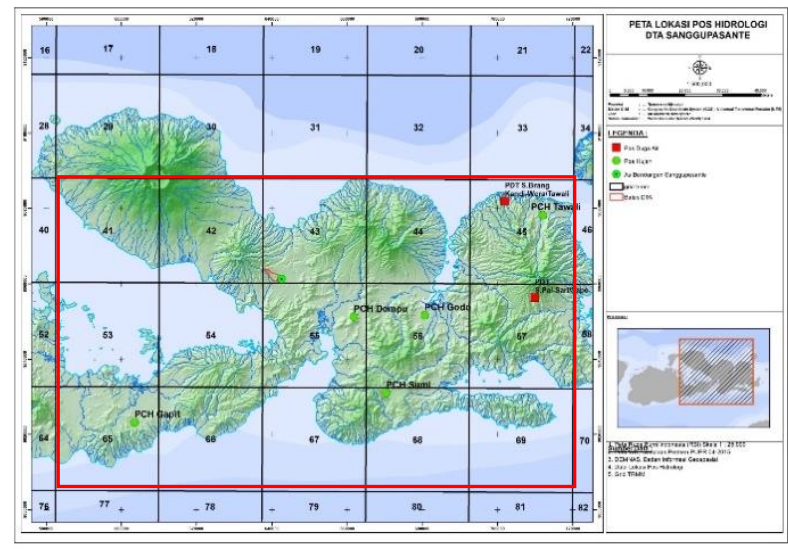

Figure 3 TRMM grid area which covered the Sanggupasante dam, the Gapit rainfall station, and the Tawali gauging station.

\section{METHODOLOGY}

The hydrological modelling is performed with three hydrograph units, i.e.: Clark's, SCS, and Snyder on daily basis. The models were implemented on the three watersheds (dam, rainfall, and water level gauging stations) with raw input from TRMM satellite data, corrected with rainfall ground station data, and calibrated against observed discharge.

\subsection{Correction of The Hydro-Meteorological Models}

First, it is confirmed that the continuous rainfall data from both the ground station and TRMM have more than 20 years of missing records of less than $5 \%$. Then, data quality from ground station rainfall data are checked by comparing ground station data with specified TRMM grid which covered ground station watershed. Data outputs are judged satisfactory when they have a correlation coefficient of more than $60 \%$ and a Root Mean Square Error (RMSE) value less than 200.

Next, preliminary analysis for correcting TRMM data for a tropical zone with ground station data could be held with the formula as follow: a) TRMM rainfall data which have $0-10 \mathrm{~mm}$ values are small and insignificant; $b$ ) for TRMM values from $50 \mathrm{~mm}$ to $100 \mathrm{~mm}$ usually have reduction about 0 - 20\% [7]; c) TRMM which have more than $100 \mathrm{~mm}$ values usually have multiplied by $1-1.3$. Furthermore, the corrected TRMM data are compared with ground station data.

\subsection{Calibration of The Hydro-Meteorological Models}

The first stage for calibration of hydrometeorological data is calculated the average value of all TRMM grids. Thus, the results are being corrected with a coefficient derived from the previous analysis. Along with that, the ground data such as elevation, slope, soil type, and land cover of those locations should be defined for developing the values of saturated hydraulic conductivity, hydrological soil group, and cumulative $\mathrm{CN}$.

Next, ground data for gauging watershed is derived for input as parameters of three hydrograph units with TRMM corrected data for developing discharge values. The calculated discharge is next being calibrated against observed discharge from the gauging station.

The three hydrological models were then validated for the reference ground values about the Nash efficiency criteria NSE [10].

$N S E=100\left\{1-\frac{\sum_{i}\left(Q_{i}^{o b s}-Q_{i}^{\text {sim }}\right)^{2}}{\sum_{i}\left(Q_{i}^{o b s}-Q_{m}\right)^{2}}\right\}$

Where $Q_{i}^{\text {obs }}$ is observed discharge and $Q_{i}^{\text {sim }}$ is simulated discharge for the month $\mathrm{i}$, and $Q_{m}$ is average observed discharge along period of the dataset.

The model outputs are judged very good when NSE value is higher than $60 \%$, good when NSE value is between $40 \%-60 \%$, satisfactory when NSE value is $20 \%$ to $40 \%$ and unsatisfactory when NSE value is less than $20 \%$.

Table 1. Correction factors calculation

\begin{tabular}{|c|c|c|c|}
\hline Rainfall interval (mm) & Correction Factor & RMSE before & RMSE after \\
\hline $0-5$ & 0.50 & \multirow{6}{*}{0.3893} & \multirow{6}{*}{0.3785} \\
\hline $5.01-30$ & 0.89 & & \\
\hline $30.01-50$ & 1.12 & & \\
\hline $50.01-60$ & 1.20 & & \\
\hline $60.01-100$ & 1.75 & & \\
\hline$>100$ & 2.07 & & \\
\hline
\end{tabular}




\section{RESULTS AND DISCUSSION}

Thus, model input is necessary for generating a reliable output. The proposed assessment comprises several stages, which are applied in series. This section summarizes each correction and calibration with statistic measurement.

\subsection{Implementation of The Hydro- Meteorological Similarity on The Rainfall Ground Station Watershed}

Data availability will be determined by the acceptability of data, calibration, and validation stages. The hydrology model will depend on ground station data if discharge records from the river. Based on the Gapit rainfall gauging station, the main period of data available for 22 years (1995 to 2016). Hence, grid TRMM data for the Gapit area (grid 65) should be exactly accessible. Next, the two correction tools (RMSE and correlation) were then applied to compare the TRMM grid and Gapit data.

Based on the analysis, the correlation value between TRMM grid 65 and Gapit data is 0.65 . It shows RMSE value after calibration is slightly less than RMSE before calibration with a total RMSE is $6.05 \mathrm{~mm}$ (less than 200 $\mathrm{mm})$.

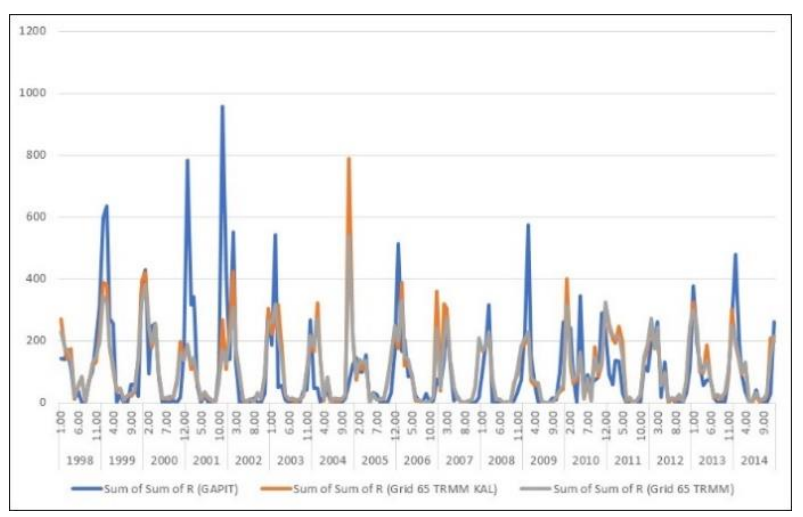

Figure 4 Comparison between TRMM grid 65 and Gapit rainfall data

\subsection{Implementation of The Hydro- Meteorological Similarity on The Reference Watershed}

After determining the coefficient factor for the reference watershed, the average rainfall data from the TRMM grid which covered the targeted watershed, rainfall station watershed, and gauging station watershed are divined as reference rainfall values.

Next, average data from all covered grid is compared with grid 65 , while both have similar patterns (see Fig. 5). Furthermore, rainfall data derived from TRMM reference are calculated with ground data characteristics of the discharge gauging watershed for developing discharge values reference using three hydrograph units.

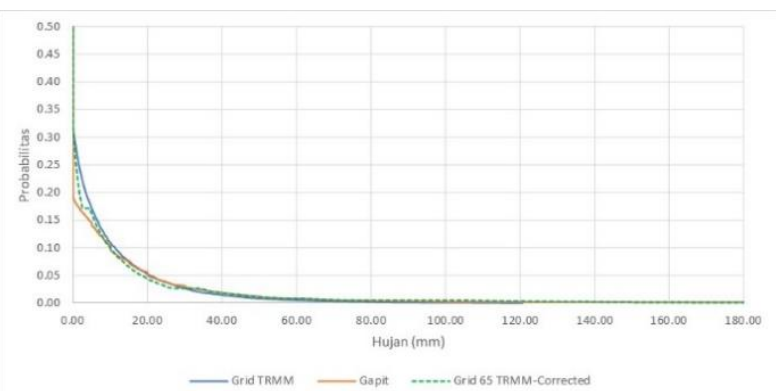

Figure 5 Probability curve between TRMM grid 65 and Gapit rainfall data

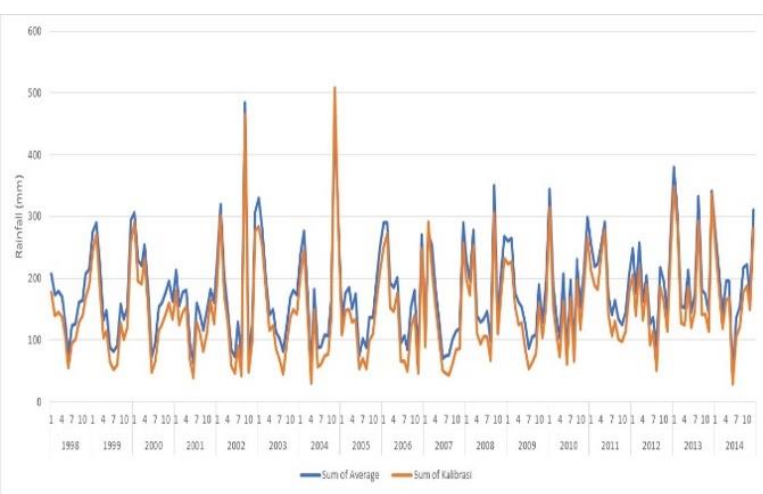

Figure 6 Comparison between TRMM grid 65 and average TRMM data

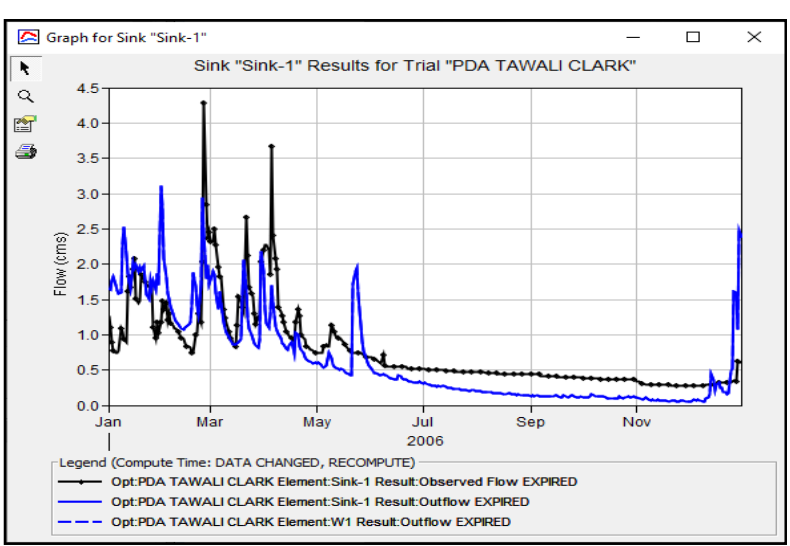

Figure 7 Calibration data Tawali discharge station with Clark's unit hydrograph 


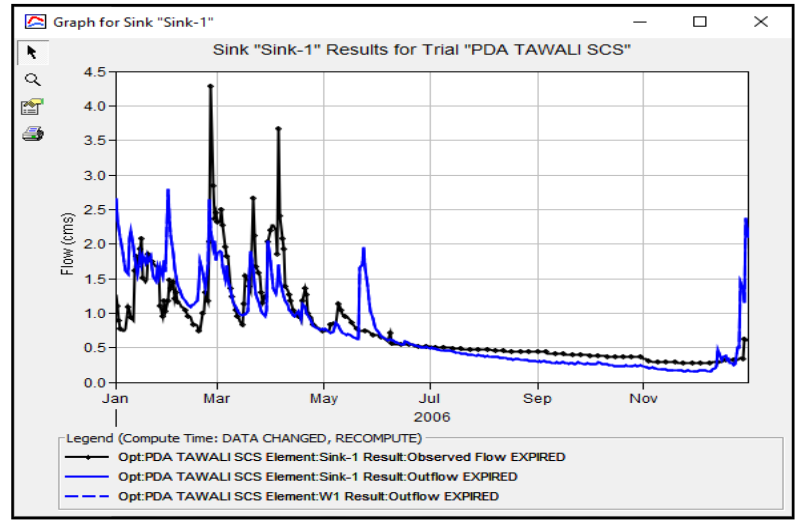

Figure 8 Calibration data Tawali discharge station with SCS unit hydrograph

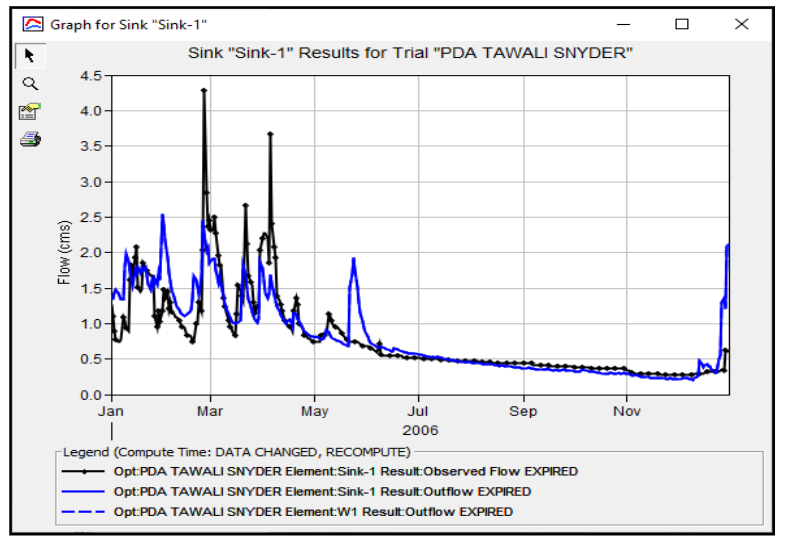

Figure 9 Calibration data Tawali discharge station with Snyder unit hydrograph

A set of three calculations were performed for the targeted watershed. The calibration is compared on Clark's, SCS, and Snyder hydrograph values with Tawali discharge data using Nash efficiency criterion (NSE). The assessment shows that Clark's UH, SCS UH, and Snyder UH have $0.385,0.528$, and 0.645 NSE values. Therefore, Snyder UH has the highest NSE value compared with others (see Table. 2).

Table 2. Rating performance

\begin{tabular}{|l|l|l|}
\hline \multicolumn{1}{|c|}{ Methods } & \multicolumn{1}{|c|}{ NSE } & \multicolumn{1}{|c|}{$\begin{array}{c}\text { Rating } \\
\text { performance }\end{array}$} \\
\hline Clark's UH & 0.385 & Satisfactory \\
\hline SCS UH & 0.528 & Good \\
\hline Snyder UH & 0.645 & Very good \\
\hline
\end{tabular}

\subsection{Prediction for the targeted ungauged watershed}

The prediction of reliable discharge for ungauged watershed was made from the assessment that the model's parameters of the reference watershed are like the targeted watershed.
The simulated reliable discharge for the Sanggupasante dam is showed that the lowest value occurred in August. Hence, the maximum discharge occurred in February with multiplied values.

Taken together, the hydrometeorological assessment shows a fair result for simulating reliable discharge from an ungauged watershed. Implementation of the three unit's hydrograph reveals a capability of the model to develop monthly reliable discharge in Sumbawa Island. The use of NSE methods for calibrating the model has shown that reliable discharge has very good performance $(64.5 \%)$

\section{CONCLUSIONS}

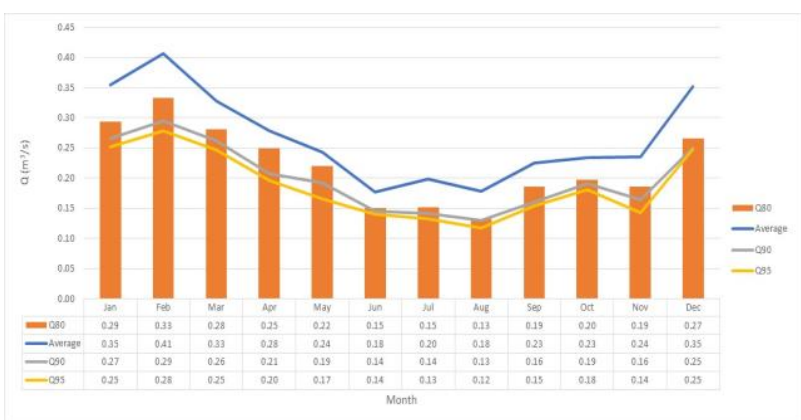

Figure 10 Reliable discharge of Sanggupasante dam

Reliable discharge has an important role in water resources management. Especially for dam simulation, this has a significant impact on improving water utilization. The ungauged watershed is also still a challenging problem in the hydrology and meteorology area. The hydro-meteorology assessment is promising to improve the reasonable methodology for developing discharge in the ungauged watershed.

However, by 2020, the Tropical Rainfall Measuring Mission (TRMM) was replaced by Global Precipitation Measurement (GPM). Therefore, in future research about satellite data, TRMM data should be extended by GPM data [13].

\section{AUTHORS' CONTRIBUTIONS}

DI - the concept of the paper, elaboration of a strategy, contribution with an overview of satellite data, model, and statistics; ARG - elaboration of a strategy, contribution with an overview of satellite data; KT elaboration of a strategy, contribution with an overview of location; BY - elaboration of a strategy, contribution with an overview of the model.

\section{ACKNOWLEDGMENTS}

This work was funded by Public Work and Housing Ministry through the "Dam Operational Improvement and Safety Project Phase 2 (DOISP-2)" project. We 
would like to thank the BWS Nusa Tenggara I for providing the rainfall and discharge data

\section{REFERENCES}

[1] G. Bloschl and M. Sivapalan, "Scale issues in hydrological modelling: A review," Hydrological Processes, vol. 9, pp. 251-290, 1995.

[2] A. R. Ganguly and R. L. Bras, "Distributed Quantitative Precipitation Forecasting Using Information from Radar and Numerical Weather Prediction Models," Journal of Hydrometeorology, vol. 4, pp. 1168-1180, 2003.

[3] A. Mosavi, M. Golshan and B. e. a. Choubin, "Fuzzy clustering and distributed model for streamflow estimation in ungauged watersheds," Nature : Scientific Reports, vol. 11, no. 1, pp. 1-14, 2021.

[4] C. Bahram, K. Solaimani and F. e. a. Rezanez, "Streamflow regionalization using a similarity approach in ungauged basins: Application of the geo-environmental signatures in the Karkheh River Basin, Iran," Catena, vol. 182, 2019.

[5] M. Sivapalan, K. Takeuchi and S. e. a. Franks, "IAHS Decade on Predictions in Ungauged Basins (PUB), 2003-2012: Shaping an exciting future for the hydrological sciences," Hydrological Sciences Journal, vol. 48, no. 6, pp. 857-880, 2010.

[6] O. Dubovik, G. L. Schuster, F. Xu and et.al, "Grand Challenges in Satellite Remote Sensing," Frontiers in Remote Sensing, vol. 2, no. doi: 10.3389/frsen.2021.619818, pp. 1-10, 2021.

[7] R. F. Adler, G. J. Huffman, D. T. Bolvin, S. Curtis and E. J. Nelkin, "Tropical Rainfall Distributions Determined Using TRMM Combined with Other Satellite and Rain Gauge Information," Journal of Applied Meteorology and Climatology, vol. 39, no. 12, p. 2007-2023, 2000.

[8] C. Kummerow, J. Simpson and e. O. Thiele, "The Status of the Tropical Rainfall Measuring Mission (TRMM) after Two Years in Orbit," Journal of Applied Meteorology and Climatology, vol. 39, no. 12, p. 1965-1982, 2000.

[9] E. D. Center, "Peta Isohit PMP Nusa Tenggara Lembar 1," Ministry of Public Work and Housing, Jakarta, 2013.

[10] J. Nash and J. Sutcliffe, "River flow forecasting through conceptual models part $\mathrm{I}-\mathrm{a}$ discussion of principles," Journal of Hydrology: Regional Studies, vol. 10, p. 282-290, 1970.

[11] D. Moriasi, J. Arnold, M. Van Liew, R. Bingner, R. Harmel and T. Veith, "Model evaluation guidelines for systematic quantification of accuracy in watershed simulations," $A S A B E$, vol. 50, pp. 885-900, 2007.

[12] B. Ibrahim, D. Wisser, B. Barry and et.al, "Hydrological predictions for small ungauged watersheds in the Sudanian zone of the Volta basin in West Africa," Journal of Hydrology: Regional Studies, vol. 4, pp. 386-397, 2015.

[13] A. Libertino, A. Sharma, V. Lakshmi and P. Claps, "A global assessment of the timing of extreme rainfall from TRMM and GPM for improving hydrologic design," Environmental research, vol. 11, no. 5, pp. 1-10, 2016.

[14] A. C. Getirana, "Integrating spatial altimetry data into the automatic calibration of hydrological models," Journal of Hydrology, vol. 387, pp. 244$255,2010$.

[15] J. M. Kult, L. M. Fry, A. D. Gronewold and W. Choi, "Regionalization of hydrologic response in the Great Lakes basin:Considerations of temporal scales of analysis," Journal of Hydrology, vol. 519, pp. 2224-2237, 2014. 